\title{
Challenges Facing Nurses While Participating in Continuing Professional Development: A Case of Western Kenya
}

\author{
Mosol Priscah ${ }^{1, *}$, Kei Robert ${ }^{2}$, Obwoge Ronald Omenge ${ }^{3}, \mathrm{Ng}^{\prime}$ eno Anne ${ }^{4}$ \\ ${ }^{1}$ Department of Midwifery and Gender, School of Nursing, College of Health Sciences, Moi University, Eldoret, Kenya \\ ${ }^{2}$ Department of Public Health, School of Health Sciences, Meru University, Meru, Kenya \\ ${ }^{3}$ Department of Community Health, Faculty of Health Sciences, Egerton University, Nakuru, Kenya \\ ${ }^{4}$ Department of Medical Education, Moi University, Eldoret, Kenya
}

Email address:

mosol.priscah@gmail.com (M. Priscah)

*Corresponding author

\section{To cite this article:}

Mosol Priscah, Kei Robert, Obwoge Ronald Omenge, Ng'eno Anne. Challenges Facing Nurses while Participating in Continuing Professional Development: A case of Western Kenya. American Journal of Nursing Science. Vol. 6, No. 4, 2017, pp. $304-307$. doi: 10.11648/j.ajns.20170604.14

Received: May 12, 2017; Accepted: May 19, 2017; Published: July 10, 2017

\begin{abstract}
Background: The context of work for nurses is rapidly changing due to changes in care, innovative technologies, and emergence of new knowledge. Participation in Continuing Professional Development (CPD) in many countries in Africa remains low. Objective: The objective of the study was to explore the challenges facing Nurses while participating in CPD in Western Kenya. Methods: A descriptive cross- sectional study design was employed where 235 stratified and randomly selected nurses and four CPD Coordinators from four County Hospitals in Western Kenya were selected. The Key informants and the respondents for Focus Group Discussions were selected purposively. Data for this research was collected using a semistructured questionnaire, interview schedules and Focus Group Discussion guide. Data analysis was done using statistical package for social sciences (SPSS V. 20). Data was summarized using frequencies; means and standard deviation. The data obtained was presented using percentage distributions, bar graphs and frequencies. Qualitative data was analysed thematically. Results: Majority of the nurses reported staff shortage 199 (85.8\%), lack of time due to heavy workload 179 (77.2\%) and lack of finance 137 (59.1\%). Other challenges included: lack of information on availability of CPD (35.8\%), family commitment (28.9\%), lack of interest (15.1\%) and distance (27.2\%). Findings from FGDs showed similar results; staff shortage and heavy workload were cited as major challenges hindering nurse's participation in CPDs. Key informants reported, lack of written policies for CPD, lack of available guidelines for CPD and lack of coordination with other CPD coordinators either at County level or at National level. Conclusion and Recommendations: The main challenges highlighted by nurses were:-staff shortages, lack of time due to heavy workload, lack of finances, night shift and lack of information on the availability of CPD. Key informants highlighted:- lack of written policies for CPD, lack of available guidelines for CPD, lack of coordination with other CPD coordinators. The study recommends employing more nurses, formulating policies affecting CPD and providing financial support to help support CPD activities. Coordinators should organize favorable time and space for CPD activities while ensuring equal opportunities are offered for participation and there is need for coordination with other CPD coordinators either at County level or at National level.
\end{abstract}

Keywords: Continuing Professional Development, CPD Activities, Challenges, CPD Coordinator

\section{Introduction}

The work context of nurses is rapidly changing due to changes in care, innovative technologies, and the emergence of new knowledge. Continuing Professional Development (CPD) for nurses has become necessary in order to maintain and improve standards of health care practice, through 
development of knowledge, skills and attitudes [8]. Even with the technological changes in health care, CPD for nurses in many countries in Africa remains low despite evidence of good practice and innovation, including planning of CPD at national level to accredited standards [21].

In as much as nurses recognize professional development as important as it contributes to personal, institutional and professional development, some personal, professional or organizational factors hinder nurses' participation in CPD activities [18]. Other studies have identified situational factors perceived by nurses as barriers to their participation in CPD [15]. These factors include lack of CPD policy by the nursing regulatory body; lack of guidelines on relevant $\mathrm{CPD}$ and accredited providers; staff shortage leading to lack of time. [7] Recommended that regional and international collaboration is needed for support in funding of CPD activities and the need to use information technology during implementation of CPD activities.

Other barriers identified in literature include:- difficulty in accessing programmes, especially for nurses working at night and those in rural areas; lack of organizational policy that promotes CPD among nurses; lack of organizational support; decreasing budgets for CPD activities in health facilities; lack of funding for expenses incurred while attending CPD; travelling distances from some programmes; non-supportive supervisors and lack of quality CPD programmes [14]. To promote Continuing Professional Development for nurses and overcome persistent barriers to participation, there is an urgent need for policy change and creation of systems, beliefs and values that promote professional development in an organization [3].

Although CPD for nurses in Kenya is currently mandatory, research has shown wide spread barriers to the successful planning, implementation, participation in and recording of CPD for nurses [12]. In a study conducted on barriers to enrolment to a nursing upgrading program in Kenya, the cost of school fees was identified as a major barrier [12].

Based on the aforementioned challenges, most health care organizations have resorted to use their limited funding to organize and conduct in-house training with hope that it would meet the changing health needs within the health care environment $[6,16]$. This creates a gap in the effectiveness of this kind of trainings in meeting the needs of an individual learner. Thus the researcher sought to investigate challenges facing nurses while participating in CPD in Western Kenya in order to inform policy.

\section{Objective}

The objective of the study was to explore challenges facing nurses while participating in CPD in Western Kenya County hospitals.

\section{Methodology}

A descriptive cross-sectional study design was used to carry out the study which was conducted in Western Kenya region. The study further adopted a mixed method approach which provided for triangulation that sought convergence and corroboration of the results from questionnaire, interviews and Focus Group Discussions (FGD). Qualitative technique provided detailed description of variables under study and was meant to support the quantitative data.

The sampling procedure of this study adopted stratified random sampling technique for the individual nurses in which the target populations of 569 respondents were grouped into four strata. In each stratum, a simple random sampling was undertaken to determine the sample.

The CPD Coordinators were sampled using purposive sampling. Again, the number of CPD Coordinators (4) was small and manageable without sampling. Therefore the total sample for the study was 239. Questionnaires, interview schedules and Focus Group Discussions were used to collect the data.

Data was summarized using frequencies, means and standard deviation for descriptive statistics. The data obtained was presented using percentage distributions, bar graphs and frequencies. The audio recorded information from focus group discussions were transcribed into written words and used for narrations. The findings from FGD and interview schedules were tallied in frequencies and summarized in words to generate themes.

Ethical approval was obtained from Institutional Research and Ethics Committee (IREC) based in Moi University and Moi Teaching and Referral Hospital. A written cover letter was distributed to the participants clarifying the purpose of the study, together with the questionnaire. Participation was voluntary and the information provided was treated with the utmost regard for confidentially and anonymity.

\section{Results}

A total of $232(98.7 \%)$ out of 235 nurses completed the questionnaire. Among them, 68(29.3\%) were aged between $31-40$ years and $177(76.3 \%)$ were female. Majority 165(71.1\%) were married and 134(57.8\%) had Diploma level of education as in table 1. the median (IQR) number of years of experience was $15(6,25)$.

Table 1. Socio-demographic information.

\begin{tabular}{lll}
\hline Characteristic & Frequency & Percent \\
\hline Age-group( in years) & & \\
$20-30$ & 52 & 22.4 \\
$31-40$ & 68 & 29.3 \\
$41-50$ & 64 & 27.6 \\
$>50$ & 48 & 20.7 \\
Gender & & \\
Male & 55 & 23.7 \\
Female & 177 & 76.3 \\
Marital status & & \\
Married & 165 & 71.1 \\
Single & 49 & 21.1 \\
Divorced & 4 & 1.7 \\
Separated & 2 & 0.9 \\
Widowed & 12 & 5.2 \\
Education level & & \\
\hline
\end{tabular}




\begin{tabular}{lll}
\hline Characteristic & Frequency & Percent \\
\hline Certificate & 41 & 17.7 \\
Diploma & 134 & 57.8 \\
Degree & 54 & 23.3 \\
Masters & 3 & 1.7 \\
\hline
\end{tabular}

Majority of the nurses reported staff shortage 199 (85.8\%), lack of time due to heavy workload 179 (77.2\%) and lack of finance 137 (59.1\%). Other challenges included: lack of information on availability of CPD (35.8\%), family commitment $(28.9 \%)$, lack of interest $(15.1 \%)$ and distance $(27.2 \%)$ as shown in table 2 below.

Table 2. Challenges faced by Nurses in Participating in CPD.

\begin{tabular}{lll}
\hline Challenge & Frequency & Percent \% \\
\hline Staff shortage & 199 & 85.8 \\
Lack of finance & 137 & 59.1 \\
Lack of time due to heavy workload & 179 & 77.2 \\
Night shift & 98 & 42.2 \\
Lack of information on availability of CPD & 83 & 35.8 \\
Family commitment & 67 & 28.9 \\
Lack of interest & 35 & 15.1 \\
Distance & 63 & 27.2 \\
\hline
\end{tabular}

Findings from FGDs showed similar results; staff shortage and heavy workload were cited as major challenges hindering nurse's participation in CPDs. At the same time even for those that manage to attend the CPDs, they reported that there was no impact at the place of work as they are not able to give feedback to their colleagues on what they had learnt during CPD due to staff shortage as one respondent said;

"..... We do attend CPDs but we rarely get time to give feedback. We would actually wish that whenever we get back to our place of work we may give some feedback to our colleagues in the department but with the staff shortage and workload, we have no time for feedback..."

Other challenges cited by the respondents focus group discussion were grouped under the following themes: bias in selection of participants, inappropriate time for CPD, lack of conducive environment for CPD, lack of financial support, lack of writing material, lack of equipment for teaching and learning, lack of motivation, lack of active involvement during selection of topics, negative attitude towards CPD by the nurses, rigidity among the old nurses and lack of transport by nurses who live far away from the hospital and those who might be off duty and power shortages among others. In addition, lack of proper communication of CPDs venue by the coordinators appeared to affect nurse's participation in CPD as a respondent during FGD mentioned that:

"... The venue changes from time to time. I recall there was a day I was waiting to see people converge at a certain place where we use to have the CMEs, only to find that it was already underway in a different place...."

Challenges highlighted by the key informants during interviews include: lack of written policies for CPD, lack of available guidelines for $\mathrm{CPD}$, lack of coordination with other CPD coordinators either at County level or at National level, lack of appropriate evaluation tools/methods for CPD and challenges in managing time.

\section{Discussion}

Findings from the study indicate that majority of the nurses reported staff shortage $(85.8 \%), 77.2 \%$ reported lack of time due to heavy workload and $59.1 \%$ reported lack of finance as challenges facing nurses while participating in CPD. The findings are consistent with findings from [17] whereby $67.7 \%$ respondents indicated staff shortages, $54.5 \%$ indicated lack of time due to heavy workload and $35.4 \%$ indicated lack of finance as barriers to CPD participation. The findings are also consistent with [18] observations, where CPD providers need to cooperate with sponsors in order to address cost as a barrier to CPD and thus increase nurses' participation in CPD activities. On the contrary, [11] found that employer payment of workshop and conference fees did not affect participation in CPD.

Findings from key informants indicated lack of proper policies, guidelines and coordination with CPD regulatory bodies as barriers to management of CPD. The findings agree with [5] who found lack of time dedicated for learning, staff shortages, lack of CPD policies, and health professionals being overwhelmed with patient care duties as barriers to CPD participation.

So long as CPD occurs where professionals seek to maintain or to improve the quality of their professional performance, other studies indicate that participant's attitudes and funding were among the external barriers to CPD uptake by nurses $[19,4,10]$. Other barriers as identified in literature include inflexible learning methods, limited time and resources, heavy work load and absence of colleagues to cover their work were reported as other barriers preventing uptake of CPD by Nurses working in night shift $[2,13,20,9]$.

The findings from FGDs are consistent with findings from [18] who identified the cost of attending CPD; family responsibilities; travel distance; under-staffing and lack of quality or interesting topics; lack of benefit in attending CPD; lack of support from administration, and peer opinions and attitudes as deterrents to participation. [1] Found financial difficulties, time constraints due to work overload and staff shortage as barriers to accessing CPD programmes.

In summary, it can be deduced from findings and the discussions that the major challenges facing nurses while participating in CPD are lack of time due to heavy workload, shortage of nurses, lack of finances and lack of guidelines and policies affecting CPD.

\section{Conclusion}

The study concluded that the challenges facing nurses while participating in CPD were; - staff shortages, lack of time due to heavy workload, lack of finances, night shift and lack of information on the availability of CPD. On the other hand, key informants highlighted: lack of written policies for 
CPD, lack of available guidelines for CPD, lack of coordination with other CPD coordinators either at County level or at National level, lack of appropriate evaluation tool/methods for CPD and challenges in time management by the nurses.

\section{Recommendations}

The study recommends that the hospital management should consider employing more nurses, formulate policies affecting CPD, provide financial support and invite sponsors to help support CPD activities. Coordinators should organize favorable time and space for CPD activities while ensuring equal opportunities are offered for participation. Coordination with other CPD coordinators either at County level or at National level is needed.

\section{References}

[1] Banning, M. \& Stafford, M. (2008). A Hermeneutic Phenomenological Study of Community. Nurses' Continuing Professional Development. British Journal of Community Nursing, 13(4): 178-182.

[2] Barribal, K. L., While, A. E. (1996). Participation in continuing professional education in Nursing: Findings of an Interview Study. Journal of Advanced Nursing.

[3] Cooper, E. (2009). Creating a Culture of Professional Development: A Milestone Pathway Tool for Registered Nurses. Journal of Continuing Education in Nursing 40, (1).

[4] Davey, B., Robinson, S. (2002). Taking a Degree after Qualifying as a Registered General Nurse: Constraints and Effects. Nurse Education Today; 22: 624-631. Elsevier Science Direct.

[5] De Villiers, M. (2008). Global Challenges in Continuing Professional Development: The South African perspective. Journal of Continuing Education in the Health Professions. 28 (S1): 26.

[6] Draper, J. (2007). Impact of Continuing Professional Education on Practice: The Rhetoric and the Reality. Nurse Education Today.

[7] Farooq, P. S. (2003). Continuing professional development for psychiatrists in Developing Countries. Advances in Psychiatric Treatment.

[8] Golding, L., \& Gray, I. (2006). Continuing Professional Development: A Brief Guide. The Psychologist. 19(9), 530532 .
[9] Hamdeh, H. A. \& Jaradeh, M. (2010). Nurses' Experiences of Continuing Professional Development: DAR Publishers, university of Jordan. $J$ Med $J$; Vol. 44 (3): 313- 322).

[10] Johnson, A. \& Copnell, B. (2002). Benefits and Barriers for Nurses Undertaking Post-Graduate Diplomas in Pediatric Nursing. Nurse Education Today; 22: 118-127. Available Elsevier Science Direct. Journal of Medical Education. Vol. 01, no. 01.

[11] Kubsch, S., Henniges, A., Lorenzoni, N., Eckardt, S \& Oleniczak, S. (2003). Factors Influencing Accruement of Contact hours for nurses. Journal of Continuing Education in Nursing, 34(5): 205-211.

[12] Lakati, A. \& Ngatia, P. (2012). Barriers to Enrolment into a Professional upgrading Programme for Enrolled Nurses in Kenya. Pan African Medical Journal. 13 (1: 10).

[13] Larcombe, K. \& Maggs, C. (1991). Process for Identifying the Continuing Professional Education Needs of Nurses, Midwives and Health visitors. An Evaluation. English National Board for Nurses, Midwives and Health Visitors. London.

[14] Mayes, P \& Schott-Baer, D. (2010). Professional Development for Night Shift Nurses. Journal of Continuing Education in Nursing, 41(1): 17-22.

[15] McCoy, C. (2009). Professional Development in Rural Nursing: Challenges and Opportunities. Journal of Continuing Education in Nursing, 40(3): 128-131.

[16] Nursing and Midwifery Council (NMC) (2000). The PREP (practice) Standard, Nursing and Midwifery Council. www.nmc-org/nmc/main/advice/thePracticeStandard.html (accessed on 27/7/2016).

[17] Onyango, D. A. (2012). Nurses' Perceptions of Continuing Professional Development in a Public Health Care Facility in Kisumu, Kenya. University of South Africa.

[18] Schweitzer, D. J \& Krassa, T. J. (2010). Deterrents to Nurses' Participation in Continuing Professional Development: An Integrative Literature Review. Journal of Continuing Education in Nursing, 41(10): 441-447.

[19] Stanley, H. (2003). The Journey to Becoming a Graduate Nurse: A Study Of The Lived Experience of Part-Time PostRegistration Students. Nurse Education in Practice. 3: 62-71.

[20] Watson, R., Manthorpe, J. \& Andrews J. (2003). Nurses Over Fifty: Options, Decisions and Outcomes. London: James Rowntree Foundation.

[21] WHO, (2010). Scaling up Education and Training of Human Resources for Health in Ethiopia. Addis Ababa, Ethiopia. 